\title{
A prospective audit on the effect of training and educational workshops on the incidence of urethral catheterization injuries
}

\author{
Nikita R. Bhatt, MD; Niall F. Davis, MD; Mark R. Quinlan, MD; Robert J. Flynn, MD; T.E.D. McDermott, MD; \\ Rustom P. Manecksha, MD; John A. Thornhill, MD
}

Department of Urology, Tallaght Hospital, Dublin, Ireland

Cite as: Can Urol Assoc J 2017;11 (7):E302-6. http://dx.doi.org/10.5489/cuaj.4271 Published online July 11, 2017

\section{Abstract}

Introduction: The incidence of iatrogenic urethral catheterization (UC) injuries is approximately $0.3 \%$. Resultant complications are associated with patient morbidity and unnecessary healthcare costs. Our aim was to investigate whether educational training workshops decreased the incidence of UC-related injuries.

Methods: A prospective audit was performed to calculate incidence, morbidity, and costs associated with iatrogenic UC injury from January to July 2015. Educational workshops were then conducted with healthcare staff and training modules for junior doctors. UC-related incidence, morbidity, and costs in the subsequent six-month period were recorded prospectively and compared with the previous data.

Results: The incidence of iatrogenic UC injuries was reduced from 4.3/1000 catheters inserted to 3.8/1000 catheters after the intervention $(p=0.59)$. Morbidity from UC increased in the second half in the form of increase in cumulative additional inpatient hospital stay ( 22 to 79 days; $p=0.25)$, incidence of urosepsis $(n=2$ to $n=4)$, and need for operative intervention $(n=1$ to $n=2)$. The cost of managing $U C$ injuries almost doubled in the period after the training intervention (€50 449 to $€ 90100$ ).

Conclusions: Current forms of educational and training interventions for UC did not significantly change morbidity or cost of iatrogenic UC injuries despite a decrease in incidence. Improved and intensive training protocols are necessary for UC to prevent avoidable iatrogenic complications, as well as a safer urethral catheter design.

\section{Introduction}

Urethral cauterization (UC) is routinely performed in hospital and community settings. Approximately 25\% of hospitalized patients are catheterized during their inpatient stay. The incidence of iatrogenic UC injuries is 6.7 per 1000 catheters inserted. ${ }^{1}$ All newly qualified doctors are expected to be safe, confident, and competent at performing UC at the end of their training. ${ }^{2}$
Current methods of UC training and examination of skill acquisition are largely simulation-based. Simulation-based training suits all learning types, and helps in better attainment and retention of procedural skills; ${ }^{3}$ however, one Irish study on UC reported that $76 \%$ of interns felt their practical training for UC was non-existent or inadequate and 52\% did not receive any supervision during their first UC. ${ }^{4}$ There is also significantly higher UC-related morbidity caused by newly qualified interns (July to January) compared to interns in their last six months of training (January to July). Recent studies have also noted that iatrogenic UC trauma is increasingly caused by experienced healthcare staff, including general practitioners, senior house officers ( $\mathrm{SHO}$ ) and registrars. ${ }^{5}$ A lack of continuous training and regular inspection of procedural skills among experienced healthcare staff may be plausible explanations. The aim of this audit was to compare incidence, morbidity, and cost of iatrogenic UC injuries in a tertiary hospital after focused training modules and educational workshops for healthcare staff on UC and avoidance of iatrogenic urethral trauma were held.

\section{Methods}

\section{Overview of study design}

An audit on iatrogenic UC injuries was performed over one year, from January 2015 to December 2015, in a tertiary university teaching hospital. Prospective data collection of iatrogenic UC injury incidence, morbidity, and cost was first performed over a six-month period by the department of urology (January 2016 to July 2016). Educational workshops and lectures were conducted to create awareness on the issue. These were aimed at all healthcare staff inclusive of newly inducted interns. This was followed by a second six-month prospective data collection of iatrogenic UC injuries by the department of urology (July 2016 to December 2016). Ethics approval was not required, as per our institution's ethics committee, as this was a quality improvement audit project. 


\section{Intervention}

Members of the urology team conducted all interventions using a didactic format to focus on types of iatrogenic trauma observed, morbidity caused, and the cost to the hospital, followed by a session on prevention of iatrogenic urethral trauma. This session focused on specific difficulties encountered during $\cup C$, their management, and early involvement of the urology service. There was practical simulation-based training for healthcare staff involved in routine male catheterization supervised by a member of the urology team. The sessions were compulsory for newly inducted intern doctors and nursing staff. The attendance was optional for the remaining non-consultant hospital doctors and consultants in hospital internal meetings, where urologists conducted educational workshops. Steps were taken to ensure improved documentation and recording of $U C$ and iatrogenic injuries. Data was prospectively maintained in the departmental database.

\section{Defining traumatic UC}

Standardized definition of iatrogenic UC injuries was used from previously published studies: ${ }^{1,5}$ physician requesting a urological consultation after difficult/failed catheter placement and at least one of the following conditions: hematuria, blood at the urethral meatus, perineal/urethral pain, cystoscopic evidence of urethral trauma, and retrograde/ antegrade urethrogram demonstrating urethral trauma. Cases with trauma from self-intermittent catheterization (SIC) and patient-inflicted trauma were excluded. Patient demographics, mode of UC injury, setting of injury, grade of healthcare professional performing the $\mathrm{UC}$, management of $\mathrm{UC}$ injuries, and additional bed days due to the injury were also recorded. The additional cost of managing the UC injury was calculated from a resource and skill utilization model in conjunction with the finance department of the hospital. The overall number of UC performed was obtained from the procurement department in the hospital.

\section{Statistical analysis}

SPSS (Version 24.0. Armonk, NY, U.S.) was used for statisti$\mathrm{cal}$ analysis. Student's t test and chi-square test were used for comparison between the two groups. A p value $<0.05$ was considered statistically significant.

\section{Results}

\section{Incidence}

A total of 25 iatrogenic UC injuries were recorded during the 12-month period, with an overall incidence of 3.8 injuries per 1000 catheters per year. The incidence of UC injuries was 4.3 per 1000 catheters per year $(n=14)$ in the first six-month period compared to 3.8 per 1000 catheters per year $(n=11)$ in the second interval $(p=0.59)$ (Fig. 1). A total of 6500 UCs are performed each year in our institution. All newly inducted interns and all clinical nurse managers attended the training workshop with further dissemination to their peers. The attendance at the two hospital meetings where this workshop was conducted was approximately $30 \%$ of the hospital workforce and included all grades of doctors, including trainees (SHOs and registrars) and consultants. This audit did make special arrangements for doctors involved in previous UC injuries to attend compulsory training sessions.

\section{Patient demographics}

All patients were male. The median age was 70 years (range 42-93) in the first group compared to 69 years (range 42-85) in the second group $(\mathrm{p}=0.533)$. Indications for UC pre- and post-intervention, respectively, were: urinary retention $(n=7$ and $n=8)$; urine output monitoring ( $n=3$ and $n=1)$; brachytherapy ( $n=1$ and $n=1)$; and change of long-term catheter $(n=3$ and $n=1)$. The grade of healthcare professionals causing $U C$ injury changed significantly $(\mathrm{p}=0.002)$, with the majority of iatrogenic UC injuries caused by registrars $(n=10,71 \%)$ in the first six-month period followed by SHOs $(n=2)$, and general practitioners $(n=2)$. The majority of $U C$ injuries were caused by SHOs $(n=9)$ in the following six-month period, with one injury each caused by registrars and general practitioners. There was no difference in the setting of injuries $(p=0.67)$, with the majority of these occurring pre- and postintervention, respectively, in the emergency department $(n=9$ and $n=5)$, followed by the wards ( $n=2$ and $n=3)$, community $(n=2$ and $n=1)$, theatre $(n=0$ and $n=1)$, and radiotherapy $(\mathrm{n}=1$ and $\mathrm{n}=1)$.

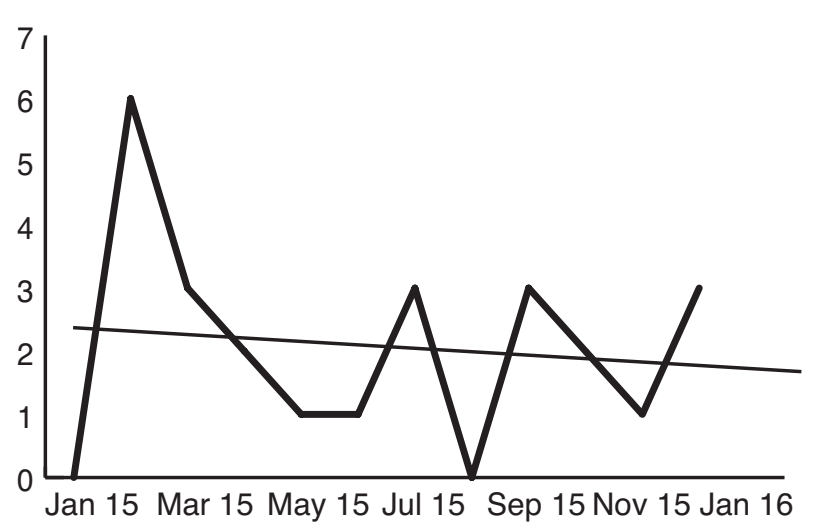

Fig. 1. Reducing incidence of urethral catheterization injury in the hospital after the intervention. 
Bhatt et al.

\section{Urethral injury sustained}

There was no significant difference in the types of urethral injury between the two six-month periods: balloon inflation in the urethra was most common $(n=8$ pre-intervention and $\mathrm{n}=6$ post-intervention), followed by false passage ( $\mathrm{n}=6$ and $\mathrm{n}=5)(\mathrm{p}=0.89)$.

\section{Acute management of UC injuries}

Management of UC injuries involved flexible cystoscopy and guidewire to catheterize the bladder, percutaneous suprapubic catheter insertion, transurethral catheter insertion by the urology service (Foley's catheter, three-way catheter and Tieman tip catheter), urosepsis management, and operative intervention (Table 1). The median additional length of stay (LOS) was three days (range 1-10, total 32) in the first sixmonth period (Table 2 ) and three days (range 1-53, total $85)$ in the second six-month period $(\mathrm{p}=0.29)$ (Table 2). The total additional LOS was 53 days higher in the latter sixmonth period.

\section{Cost}

The cost of managing $\cup C$ injuries almost doubled in the sixmonth period after the intervention, from $€ 50449$ (Table 2) to $€ 91248$ (Table 2). ${ }^{6-8}$

\section{Discussion}

Urinary catheter insertion is performed by healthcare professionals across different grades and specialties. Ideally, interns are expected to be proficient in this skill by the end of their internship year; however, several studies report low confidence in inserting a $U C$ among junior doctors and less than

\begin{tabular}{lcc}
\hline $\begin{array}{l}\text { Table 1. Comparison of acute UC injury management } \\
\text { before and after intervention }\end{array}$ & $\begin{array}{c}\text { January-July } \\
\text { (n=14) }\end{array}$ & $\begin{array}{c}\text { July-December } \\
(\mathbf{n}=\mathbf{1 1 )}\end{array}$ \\
\hline $\begin{array}{l}\text { Intervention } \\
\mathbf{p}=\mathbf{0 . 5 9}\end{array}$ & 9 & 4 \\
\hline $\begin{array}{l}\text { Flexible cystoscopy and guide } \\
\text { wire insertion of UC }\end{array}$ & 5 & 4 \\
$\begin{array}{l}\text { Percutaneous suprapubic } \\
\text { catheterization }\end{array}$ & & \\
$\begin{array}{l}\text { Catheter insertion including } \\
\text { Foley, Tiemann tip, and three- }\end{array}$ & 2 & 3 \\
$\begin{array}{l}\text { way catheter } \\
\text { Rigid cystoscopy and guidewire }\end{array}$ & 0 & 1 \\
$\begin{array}{l}\text { Open cystotomy } \\
\text { Laparotomy for perforated }\end{array}$ & 0 & 1 \\
bladder & 1 & 0 \\
$\begin{array}{l}\text { ICU admission } \\
\text { Urosepsis management }\end{array}$ & 1 & 1 \\
\hline ICU: intensive care unit; UC: urethral catheterization. & 2 & 4 \\
\hline
\end{tabular}

adequate exposure to UC training in medical school. ${ }^{9}$ This lack of confidence and insufficient experience is reflected by the fact that one in five first-year U.K. interns had never performed male catheterization and nearly half $(45 \%)$ had never performed a female catheterization after one year of medical practice. ${ }^{10}$ Studies on iatrogenic UC injuries tend to focus on interns and interventions for prevention are usually aimed at this grade of healthcare professional. Increasing clinical experience is thought to reduce the chance of causing an iatrogenic UC injury. Interestingly, the present study demonstrated that all 25 UC injuries were caused by more experienced grades of doctors who are routinely in involved in UC. These findings suggest that correct technique and appropriate training of those routinely involved in these procedures, as well as auditing of iatrogenic injuries with a view to focused training sessions is necessary in the future.

We introduced a hospitalwide training intervention for all healthcare professionals involved in UC insertion in our institution by providing education on iatrogenic $U C$ injuries and methods for prevention. A hospitalwide quality improvement intervention for $U C$ injuries is a novel concept and was difficult to implement. It was challenging to involve all grades of doctors, especially higher grades (including SHOs, registrars, and general practitioners) in the intervention, as there are fewer platforms to engage with them and compulsory attendance could not be demanded owing to working hours. We could successfully implement this program among interns and nurses; consequently, none of the injuries caused here involved interns or nurses. Incidence of iatrogenic UC injuries decreased by $0.5 / 1000$ catheters per year following the educational intervention. Although the median additional LOS due to these injuries remained constant postintervention, the total LOS increased by 53 bed-days. This was due to one patient in the post-intervention phase that had a prolonged hospital stay due to severe urosepsis secondary to false passages from multiple UC attempts. His total inpatient stay was 53 days. The study also highlighted significant costs borne by the hospital due to these injuries, the total sum of which was $€ 141697$ per year.

Although simulation-based training is beneficial in certain procedures, such as laparoscopy, there are reports that do not support the benefit of simulation-based UC training in its current form in a clinical setting. ${ }^{10}$ It is difficult to replicate UC insertion in the simulation setting and the current models do not provide typical challenges encountered in a living patient, such as urethral tortuosity in males with its angulations, enlarged prostate, high bladder neck, and possibility of false passage with greater insertion forces. Limitations with conventional simulation models highlight the need for the development of more representative UC simulation models and designs. The Male-Cath Ed1 simulator $^{11}$ by Life/form ${ }^{\circledR}$ provides a realistic anatomical urethral simulation and provides both visual and tactile feedback to trainees performing 


\begin{tabular}{|c|c|c|c|c|c|}
\hline Resource/skill & Cost (in Euros) & $\begin{array}{l}\text { Number of } \\
\text { patients: Pre- } \\
\text { intervention }\end{array}$ & $\begin{array}{l}\text { Total cost (in Euros): } \\
\text { Pre-intervention } \\
\quad(n=50675)\end{array}$ & $\begin{array}{l}\text { Number of } \\
\text { patients: Post- } \\
\text { intervention }\end{array}$ & $\begin{array}{l}\text { Total cost (in Euros): } \\
\text { Post-intervention } \\
\text { (n=91 248) }\end{array}$ \\
\hline Added hospital stay ${ }^{a}$ & & & 33005 & & 83344 \\
\hline Intensive care unit & 2936/night & 1 (5 nights) & & $2(6)$ & \\
\hline Ward & 832/night & 6 (22 nights) & & $10(79)$ & \\
\hline Procedural costsa & & & 10300 & & 5540 \\
\hline Flexible cystoscopy & 130 & 10 & 1300 & 8 & 1040 \\
\hline $\begin{array}{l}\text { Surgical theatre (weekend/ } \\
\text { emergency) }\end{array}$ & $3000 /$ hour & $\begin{array}{l}1 \text { (3-hour } \\
\text { procedure) }\end{array}$ & 9000 & 2 (1.5 hours) & 4500 \\
\hline Radiological imaging ${ }^{\mathrm{b}}$ & & & 475 & & 225 \\
\hline Computerized tomography scan & 250 & 1 & & 0 & \\
\hline Fluoroscopic cystogram & 225 & 1 & 225 & 1 & 225 \\
\hline Transfer cost (ambulance) ${ }^{c}$ & $6.5 / \mathrm{km}$ & 7 & 2571 & 0 & \\
\hline Skill cost & & & 1900 & & 900 \\
\hline In-patient urology consult* & 200 & 6 & 1200 & 4 & 800 \\
\hline $\begin{array}{l}\text { Emergency department management } \\
\text { for transferred patients }{ }^{d}\end{array}$ & 100 & 8 & 700 & 1 & 100 \\
\hline Equipment cost ${ }^{\mathrm{a}}$ & & & 679 & & 679 \\
\hline Guidewire & 42 & 7 & 294 & 4 & 168 \\
\hline Catheters & $20-65$ & 13 & 385 & 11 & 591 \\
\hline \multicolumn{6}{|l|}{ Followup cost ${ }^{\mathrm{a}}$} \\
\hline Outpatient followup & 140/visit & 11 & 1540 & 4 & 560 \\
\hline
\end{tabular}

UC. Cross-sections also allow trainees to recognize the areas of urethral restriction where there would be a high possibility of urethral injury. Studies are required to test the effectiveness of such training models in reducing UC-related injuries.

Patient demographics, mechanism, nature, and management of these injuries did not differ significantly between both time periods. This highlights that most iatrogenic UC injuries occur in a similar way in high-risk older males with difficult catheterization scenarios, such as high bladder neck, enlarged prostate, strictures, etc. Hence, education and awareness regarding this could possibly avoid future incidents.A large number of the iatrogenic UC injuries occurred in the emergency department. Wilette et al ${ }^{12}$ constructed a difficult catheterization algorithm for emergency medicine doctors to recognize possible difficulties, such as high bladder neck, enlarged prostate, and urethral stricture, to enable timely urological input. There is also an overall lack of knowledge of special catheters that can be used in this setting, such as coude-tipped catheters. Wider education and application of such guidelines may also assist in reduction of iatrogenic trauma.

Apart from morbidity, iatrogenic UC injuries pose an avoidable cost to the healthcare system. ${ }^{1,5}$ There is a growing need to devise, construct, and introduce safer catheters with protective safety mechanisms. At present, the most widely used urethral catheter was devised by Foley in 1929 and its design was finalized and patented in $1936 .{ }^{13}$ Since then, no significant modification has occurred for improving the design of urethral catheters. The modern Foley's catheter (1980s) is coated with a silicone elastomer to reduce latex toxicity of the original device. Catheter research in the last few years has largely focused on reducing urinary tract infections by coating antiseptic or antimicrobial agents over the catheter. A novel safety syringe catheter devised by Davis et al provides a protective mechanism to reduce UC injuries by controlling the threshold inflation pressure and is being currently tested in the clinical setting. ${ }^{14}$ In view of the significant morbidity caused by urinary catheters, there is a clinical need to provide a research agenda for developing a safer alternative. ${ }^{13}$

\section{Conclusion}

This study highlights the imminent need for more intensive training and better simulation models for $\mathrm{UC}$ insertion. We also emphasize the role for the development of safer urinary catheters in the near future.

Competing interests: The authors report no competing personal or financial interests.

This paper has been peer-reviewed. 
Bhatt et al.

\section{References}

1. Davis NF, Quinlan MR, Bhatt NR, et al. Incidence, cost, complications, and clinical outcomes of iatrogenic urethral catheterization injuries: A prospective multi-institutional study. J Urol 2016;196:1473-7. https://doi.org/10.1016/i.juro.2016.05.114

2. National intern training program (NITP): Education and training in the intern year. Available at http://www.medicalcouncil.ie/Education/Career-Stage-Intern/National-Intern-Training-Programme-pdf. Accessed June 7, 2017.

3. Waters PS, McVeigh T, Kelly BD, et al. The acquisition and retention of urinary catheterization skills using surgical simulator devices: Teaching method or student traits. BMC Med Educ 2014;14:264. https://doi.org/10.1186/s12909-014-0264-3

4. Thomas AZ, Giri SK, Meagher D, et al. Avoidable iatrogenic complications of urethral catheterization and inadequate intern training in a tertiary care teaching hospital. BJU Int 2009;104:1109-12. https://doi.org/10.1111/i.1464-410x.2009.08494.x

5. Bhatt NR, Davis NF, Addie D, et al. Evaluating the cost of iatrogenic urethral catheterization iniuries. Ir J Med Sci 2016 [Epub ahead of print]. https://doi.org/10.1007/s1 1845-016-1451-5

6. Clinic B. Insurance and financial information. Available at http://www.blackrock-clinic.ie/emergencydepartment/what-doessit-cost/. Accessed July 4, 2017

7. Euromedic. Prices. Available at https://www.affidea.ie/prices/. Accessed July 4, 2017.

8. Health Service Executive. Hospital charges 2013. Available at http://www.hse.ie/eng/services/list/3/ acutehospitals/hospitals/Hospitalcharges.html. Accessed July 4, 2017
9. Manalo M, Lapitan MCM, Buckley BS. Medical interns' knowledge and training regarding urethral catheter insertion and insertion-related urethral injury in male patients. BMC Med Educ 2011;11:1-5. https://doi.org/10.1186/1472-6920-11-73

10. Cetti RJ, Singh R, Bissell L, et al. The urological foot soldier: Are we equipping our foundation-year doctors? Ann R Coll Surg Engl 2010;92.

11. Available at male-cath-ed-i-simulator-w44663-nasco-ff01025u,p_1057 9042.html. Accessed July 4, 2017.

12. Willette PA, Coffield $S$. Current trends in the management of difficult urinary catheterizations. West $J$ Emerg Med 2012;13:472-8. https://doi.org/10.5811/westiem.2011.11.6810

13. Feneley RCL, Hopley IB, Wells PNT. Urinary catheters: History, current status, adverse events, and research agenda. J Med Eng Technol 2015;39:459-70. https://doi.org/10.3109/03091902.2015.1085600

14. Davis NF, Mooney RO, Cunnane CV, et al. Preventing urethral trauma from inadvertent inflation of catheter balloon in the urethra during catheterization: Evaluation of a novel safety syringe after correlating trauma with urethral distension and catheter balloon pressure. J Urol 2015;194:1138-45. https://doi.org/10.1016/i.juro.2015.02.083

Correspondence: Dr. John A. Thornhill, Department of Urology, Tallaght Hospital, Dublin, Ireland; thornhill.johna@gmail.com 